\title{
Efeitos de sistemas de colheita e de aplicação de fungicidas no desempenho da soca do arroz irrigado
}

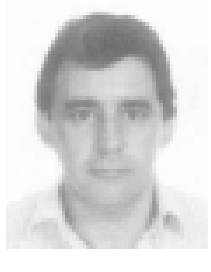

Alberto B. dos Santos ${ }^{1} \&$ Anne S. Prabhu ${ }^{2}$

\author{
1 Embrapa Arroz e Feijão. CP 179, CEP 75375-000, Santo Antônio de Goiás, GO. Fone: (62) 533-2153. \\ E-mail: baeta@cnpaf.embrapa.br (Foto) \\ ${ }^{2}$ Embrapa Arroz e Feijão. E-mail: prabhu@cnpaf.embrapa.br
}

Protocolo 100 - 17/7/2002 - Aprovado em 10/9/2003

\begin{abstract}
Resumo: O cultivo da soca de arroz pode constituir-se em uma fonte de renda significativa; entretanto, para o seu êxito é necessário um sistema de colheita adequado da cultura principal. Com o objetivo de se avaliar a resposta da soca da cultivar Epagri 108 de arroz irrigado aos equipamentos da colhedora, alturas de corte, manejos da palhada após a colheita mecanizada e fungicidas, conduziram-se experimentos por dois anos consecutivos. No primeiro ano, foram avaliados três equipamentos de colhedoras: picador de palha, espalhador de palha e sem picador e espalhador de palha; duas alturas de corte e quatro tratamentos fungicidas e, no segundo ano, além dos equipamentos de colheita foram avaliados também três manejos da palhada: passada de rolo compactador; passada de roçadora e sem manejo, e cinco tratamentos fungicidas. $O$ picador de palha propiciou melhor qualidade e maior produtividade de grãos, em comparação com o sistema de colheita em que não se o utiliza. A roçadora danificou os colmos das plantas, reduzindo o perfilhamento e a produtividade, enquanto os fungicidas proporcionaram maior produtividade e menor incidência de doenças nos grãos e, conseqüentemente, melhor qualidade do produto colhido. $O$ rolo compactador não trouxe benefícios ao crescimento nem à produtividade da soca de arroz irrigado, ao passo que o espalhador de palha apenas em menor altura de corte.
\end{abstract}

Palavras-chave: Oryza sativa, equipamento de colhedora, manejo da palhada, produtividade de grãos, rendimento industrial de grãos, qualidade tecnológica dos grãos

\section{Effect of harvesting systems and fungicide application on the performance of irrigated ratoon rice}

\begin{abstract}
The cultivation of ratoon rice may constitute a source of additional income. However, to make it economically viable an adequate harvesting system of the main crop is necessary. With the objective of evaluating the response of irrigated ratoon rice to the harvest equipment, cutting height, management of stubble after harvest and fungicides, experiments were conducted during two consecutive years. In the first year, harvesters with three types of equipment (straw chopper, straw spreader, without chopper and spreader); two heights of cutting and four fungicide treatments were evaluated. In the second year, besides harvest equipments three stubble management practices (compactor roll, straw chaffer and without management) and five fungicide treatments were assessed. The straw chopper was superior in increasing the grain yield and quality, in comparison with normal harvest without utilizing this equipment. The fungicide applications increased grain yield and reduced incidence of grain discoloration and consequent improvement in quality of the product. The roll compactor did not contribute to growth and yield of irrigated ratoon rice crop. The straw spreader increased yield only when the cutting height was low.
\end{abstract}

Key words: Oryza sativa, harvest equipment, management of stubble, grain yield, milling quality, grain quality

\section{INTRODUÇÃO}

O uso intensivo e racional de várzeas compreende a utilização de sistemas de cultivos múltiplos, produzindo duas a três safras por ano, numa mesma área. As plantas de arroz têm a capacidade de regenerar novos perfilhos férteis após o corte dos colmos na colheita. Esta brotação, denominada soca, possibilita o segundo cultivo de arroz, o qual pode constituirse numa alternativa prática para aumentar a produtividade de grãos em muitos agroecossistemas, principalmente em várzeas, visto que esta é a espécie mais adaptada (Santos, 1999). Sem a necessidade de preparo do solo nem de semeadura, o seu cultivo usa $60 \%$ menos água e $50 \%$ menos trabalho que a cultura principal. Com o desenvolvimento de técnicas adequadas aos 
diferentes sistemas de cultivo, acredita-se que o cultivo da soca possa contribuir substancialmente para aumentar a produção de arroz e, conseqüentemente, atender à crescente demanda por este cereal, pelo rápido aumento da população. Com isso, além do desenvolvimento de genótipos mais produtivos nas duas colheitas, com boa qualidade de grãos, é necessário determinar as técnicas culturais adequadas para o cultivo da soca.

Práticas culturais que promovem uma rápida e uniforme brotação, são especialmente importantes. O sistema de colheita influencia substancialmente o comportamento da soca, tanto a produtividade como a qualidade do produto colhido, devido à ocorrência de doenças. Dentre as práticas empregadas na colheita da cultura principal que afetam o comportamento da soca de arroz, destacam-se a época e a altura de corte das plantas (Chauhan et al., 1985).

A altura da resteva, parte enraizada da planta de arroz após a ceifa, determina o número de gemas úteis (Chauhan et al., 1985) e a origem dos perfilhos da soca (Vergara et al., 1988). Os efeitos da altura de corte sobre o vigor da soca são variáveis, dependendo da cultivar usada. Algumas cultivares apresentam maior brotação nos nós superiores, outras nos nós da base, não sendo afetadas pela altura de corte.

O objetivo deste estudo foi verificar os efeitos de diferentes equipamentos da colhedora, de alturas de corte, de manejos da palhada após a colheita mecanizada e de fungicidas sobre o comportamento da soca de arroz irrigado.

\section{MATERIAL E MÉTODOS}

O experimento foi realizado por dois anos consecutivos, em área de produção da cultivar Epagri 108, na Fazenda Tio Jorge, no município da Lagoa da Confusão, TO, 1998/99, e na Fazenda Xavante, em Dueré, TO, 1999/00, em solo classificado como Laterita Hidromórfica. O sistema de semeadura usado foi o de linhas espaçadas $0,17 \mathrm{~m}$ com 80 sementes por metro. $\mathrm{Na}$ cultura principal foram empregadas as técnicas recomendadas para o sistema de cultivo de arroz irrigado (Vieira et al., 1999).

No primeiro ano, avaliaram-se o uso de colhedoras com três tipos de equipamentos: $\mathrm{E}_{1}$ - com picador de palha; $\mathrm{E}_{2}$ - com espalhador de palha e $E_{3}$ - sem picador e sem espalhador de palha; duas alturas de corte: $A_{1}-0,52 m$ e $A_{2}-0,30 m$ e quatro tratamentos fungicidas: $\mathrm{F}_{1}$ - sem fungicida; $\mathrm{F}_{2}$ - difenoconazole, 100 g i.a. ha- $; \mathrm{F}_{3}$ - propiconazole, $125 \mathrm{~g}$ i.a. ha ${ }^{-1} \mathrm{e}_{4}$ trifloxistrobin, $65,5 \mathrm{~g}$ i.a. $\mathrm{ha}^{-1}+$ propiconazole $150 \mathrm{~g}$ i.a. ha- ${ }^{-1}$, e feitas duas aplicações dos fungicidas, a primeira realizada uma semana após a colheita, e a segunda uma semana antes da emissão das panículas da soca. O delineamento experimental foi o de blocos ao acaso, com quatro repetições, no esquema de parcelas sub-subdivididas. As parcelas foram constituídas pelos equipamentos de colheita e compreenderam a largura de duas passadas da colhedora, aproximadamente $10 \mathrm{~m}$, por $80 \mathrm{~m}$ de comprimento, as subparcelas pelas alturas de corte, e as sub-subparcelas, pelos fungicidas, com área de $10 \mathrm{~m}^{2}$.

No segundo ano, além dos equipamentos de colheita, avaliaram-se três manejos da palhada: $\mathrm{TP}_{1}$ - passada de rolo compactador; $\mathrm{TP}_{2}$ - passada de roçadora e $\mathrm{TP}_{3}$ - sem manejo, e cinco tratamentos fungicidas: $\mathrm{F}_{1}$ - sem fungicida; $\mathrm{F}_{2}-1^{\mathrm{a}}$ aplicação de difenoconazole, 100 g i.a. ha ${ }^{-1}$ e $2^{a}$ aplicação de difenoconazole, $100 \mathrm{~g}$ i.a. ha $\mathrm{h}^{-1}+$ carbendazin, $250 \mathrm{~g}$ i.a. ha ${ }^{-1}$; $\mathrm{F}_{3}$ - duas aplicações de trifloxystrobin, $125 \mathrm{~g}$ i.a. ha ${ }^{-1}+$ difenoconazole, $100 \mathrm{~g}$ i.a. ha- ${ }^{-1} \mathrm{~F}_{4}$ - duas aplicações de trifloxystrobin, $125 \mathrm{~g}$ i.a. ha ${ }^{-1}$, + propiconazole, $150 \mathrm{~g}$ i.a. ha ${ }^{-1}$; $\mathrm{F}_{5}-1^{\mathrm{a}}$ aplicação de difenoconazole, $100 \mathrm{~g}$ i.a. ha ${ }^{-1}$ e $2^{\mathrm{a}}$ aplicação de difenoconazole, $100 \mathrm{~g}$ i.a. ha ${ }^{-1}+$ tricyclazole, $187 \mathrm{~g}$ i.a. ha ${ }^{-1}$. As pulverizações foram realizadas na mesma ocasião do ano anterior. O delineamento experimental foi o de blocos ao acaso, com três repetições, no esquema de parcelas sub-subdivididas. As parcelas foram constituídas pelos equipamentos de colheita, compreendendo a largura de três passadas da colhedora com, aproximadamente, $15 \times 25 \mathrm{~m}$ de comprimento; as subparcelas, pelos manejos da palhada, com 5 x $25 \mathrm{~m}$; as sub-subparcelas, pelos fungicidas, com $5 \times 5 \mathrm{~m}$. O corte das plantas da cultura principal foi realizado a cerca de $25 \mathrm{~cm}$ acima do nível do solo (Santos et al., 1999). Logo após a colheita da cultura principal, os colmos remanescentes receberam 27 e $45 \mathrm{~kg} \mathrm{ha}^{-1}$ de $\mathrm{N}$ na forma de uréia nos primeiro e segundo anos, respectivamente, e a irrigação foi reiniciada.

O índice de colheita foi obtido pela relação entre a produção de grãos e a de matéria seca total em $1 \mathrm{~m}^{2}$. Por ocasião da colheita da soca, foram determinados o índice de ocorrência de mancha-parda, causada pelo fungo Drechslera oryze (Breda de Haan) (Prabhu et al., 1999) na folha bandeira e nos grãos, o número de perfilhos e de panículas por $\mathrm{m}^{2}$, o número de grãos e de espiguetas vazias por panícula, a massa de 100 grãos, a altura de plantas, o rendimento industrial de grãos e a produção de grãos, a qual foi expressa em $\mathrm{kg} \mathrm{ha}^{-1}$, após ajustada em $13 \%$ de umidade.

Efetuaram-se, também, análises de qualidade tecnológica dos grãos, como rendimento industrial dos grãos, "centro branco", classificação visual, temperatura de gelatinização e teor de amilose.

\section{RESULTADOS E DISCUSSÃO}

A produtividade da cultura principal foi, no primeiro ano, de $5751 \mathrm{~kg} \mathrm{ha}^{-1}$, com 83 grãos por panícula, massa média de 100 grãos de $2,68 \mathrm{~g}$, rendimento de grãos inteiros de $40 \%$, ocorrendo $28 \%$ de esterilidade de espiguetas, devido à alta incidência de brusone nas panículas. Certamente, a presença do fungo na cultura principal constituiu foco para a disseminação da doença na soca, afetando o seu desenvolvimento e causando redução na produtividade de grãos.

A altura de corte não teve influência na produtividade de grãos da soca, mas apenas sobre a altura das plantas da soca, discordando de Santos et al. (1999) que obtiveram maiores produtividades na soca em menores alturas de corte. O corte efetuado a $30 \mathrm{~cm}$ do nível do solo propiciou menor altura da soca (Tabela 1). Houve interação entre os equipamentos de colheita e as alturas de corte sobre o número de panículas por área (Tabela 2). Sem o uso de equipamento picador e espalhador de palha, ocorreu redução significativa no número de panículas por $\mathrm{m}^{2}$, quando se reduziu a altura de corte de $52 \mathrm{~cm}$ para $30 \mathrm{~cm}$. Como se esperava, o maior efeito da altura de corte sobre o perfilhamento se verificou neste tratamento, pois há formação de leira de palha que dificulta o crescimento dos perfilhos. 
Quanto menor a altura de corte, $30 \mathrm{~cm}$, maior foi a quantidade de palha que ficou sobre os colmos remanescentes da planta de arroz, reduzindo a brotação. O uso de espalhador de palha mostrou-se desnecessário quando a altura de corte foi de 52 $\mathrm{cm}$, mas aumentou significativamente a produção de panículas na altura de corte de $30 \mathrm{~cm}$. O uso do picador de palha apresentou-se como a melhor alternativa, pois resultou em maior perfilhamento, independente da altura de corte.

Tabela 1. Efeitos da altura de corte sobre a altura de plantas e a produtividade de grãos da soca de arroz irrigado ${ }^{1}$

\begin{tabular}{ccc}
\hline Altura de Corte & Altura de Plantas \\
\hline \multicolumn{2}{c}{$\mathrm{cm}$} \\
\hline 52 & $70 \mathrm{a}$ \\
30 & $65 \mathrm{~b}$ \\
\hline
\end{tabular}

${ }^{1}$ Médias seguidas pela mesma letra não diferem a 5\% de probabilidade pelo teste de Tukey

Tabela 2. Efeito da interação entre equipamento de colheita e altura de corte sobre o número de panículas por $\mathrm{m}^{2}$ da soca de arroz irrigado ${ }^{1}$

\begin{tabular}{lcc}
\hline \multirow{2}{*}{ Equipamento de Colheita } & \multicolumn{2}{c}{ Altura de Corte $(\mathrm{cm})$} \\
\cline { 2 - 3 } & \multicolumn{2}{c}{52} \\
\cline { 2 - 3 } & \multicolumn{2}{c}{ Panículas $\left(\mathrm{m}^{-2}\right)$} \\
\hline Picador de palha & $373 \mathrm{aA}$ & $390 \mathrm{aA}$ \\
Espalhador de palha & $312 \mathrm{bA}$ & $326 \mathrm{bA}$ \\
Sem picador e espalhador & $339 \mathrm{bA}$ & $281 \mathrm{cB}$ \\
\hline
\end{tabular}

${ }^{1}$ Médias seguidas pela mesma letra minúscula, na vertical, ou maiúscula, na horizontal, não diferem a $5 \%$ de probabilidade, pelo teste de Tukey

Não houve diferença significativa entre as produtividades de grão da soca dos tratamentos fungicidas; apenas ocorrem estas que foram superiores à testemunha, o que foi refletido pelo maior rendimento industrial de grãos, número de grãos por panícula, porcentagem de fertilidade de espiguetas e massa de 100 grãos (Tabela 3). $\mathrm{O}$ tratamento $\mathrm{F}_{4}$, duas aplicações de trifloxistrobin e propiconazole, propiciou significativamente maior rendimento industrial de grãos, inteiros e totais, que os demais. O número de grãos por panícula, a porcentagem de fertilidade de espiguetas e a massa de grãos não diferiram em razão das diferentes aplicações de fungicidas.

Verifica-se, na Tabela 4, que no tratamento que possuía leira mais espessa de palha sobre os colmos das plantas de arroz após o corte $\left(\mathrm{E}_{3} \mathrm{~A}_{2}\right)$, obteve-se a menor produtividade de grãos. Provavelmente, a palha dificultou o desenvolvimento dos perfilhos da soca, além de impossibilitar os efeitos dos fungicidas no controle de doenças, pois a leira de palha teve efeito de proteção, "guarda-chuva", dificultando o contato dos fungicidas com os colmos remanescentes. $\mathrm{O}$ uso de espalhador de palha mostrou-se desnecessário quando a altura de corte foi de $52 \mathrm{~cm}$, mas aumentou significativamente a produtividade de grãos na altura de corte de $30 \mathrm{~cm}$. O emprego do picador de palha apontou como a melhor alternativa, pois resultou em maior produtividade de grãos, independente da altura de corte. A colheita realizada com picador de palha $\left(\mathrm{E}_{1}\right)$ propiciou produtividade média de grãos de arroz na soca, em ambas as alturas de corte, $59 \%$ superior aos demais sistemas de colheita, mostrando que, mesmo com o corte mais baixo que deixa maior volume de palha, $\mathrm{A}_{2}$, não houve formação de leira de palha sobre os colmos das plantas de arroz.

Tabela 4. Efeito da interação entre equipamento de colheita e altura de corte sobre a produtividade da soca de arroz irrigado ${ }^{1}$

\begin{tabular}{|c|c|c|}
\hline \multirow{3}{*}{ Equipamento de Colheita } & \multicolumn{2}{|c|}{ Altura de Corte $(\mathrm{cm})$} \\
\hline & 52 & 30 \\
\hline & \multicolumn{2}{|c|}{ Produtividade de Grãos $\left(\mathrm{kg} \mathrm{ha}^{-1}\right)$} \\
\hline Com picador de palha & $1268 \mathrm{aA}$ & $1118 \mathrm{aA}$ \\
\hline Espalhador de palha & $693 \mathrm{cA}$ & $807 \mathrm{bA}$ \\
\hline Sem picador e sem espalhador & $932 \mathrm{bA}$ & $567 \mathrm{cB}$ \\
\hline
\end{tabular}

${ }^{1}$ Médias seguidas pela mesma letra minúscula, na vertical, ou maiúscula, na horizontal, não diferem a $5 \%$ de probabilidade, pelo teste de Tukey

Tabela 3. Efeitos de fungicidas sobre a produtividade e outras características agronômicas da soca de arroz irrigado, nos dois anos ${ }^{1}$

\begin{tabular}{|c|c|c|c|c|c|c|c|c|c|}
\hline & Fungicidas & $\begin{array}{l}\text { Dosagem } \\
\left(\text { g i.a. ha }^{-1}\right)\end{array}$ & $\begin{array}{l}\text { Produtividade } \\
\left(\mathrm{kg} \mathrm{ha}^{-1}\right)\end{array}$ & $\begin{array}{l}\text { Rendimento } \\
\text { de Grãos } \\
\text { Inteiros }\end{array}$ & $\begin{array}{l}\text { Rendimento } \\
\text { Industrial de } \\
\text { Grãos }\end{array}$ & $\begin{array}{c}\text { Fertilidade de } \\
\text { Espiguetas }\end{array}$ & $\underset{\left(n^{\circ} \operatorname{pan}^{-1}\right)}{\text { Grãos }}$ & $\begin{array}{l}\text { Massa de } \\
100 \text { Grãos }\end{array}$ & $\begin{array}{c}\text { Grãos } \\
\text { Manchados }\end{array}$ \\
\hline & & & & & $(\%)$ & & & & \\
\hline A. $\mathrm{Pr}$ & meiro ano & & & & & & & & \\
\hline $\mathrm{F}_{4}$ & $\begin{array}{l}1^{\mathrm{a}} \mathrm{Apl} \text { trifloxistrobin } \\
2^{\mathrm{a}} \mathrm{Apl} \text { propiconazole }\end{array}$ & $65,5+150$ & $1031 \mathrm{a}$ & $41,0 \mathrm{a}$ & $59,0 \mathrm{a}$ & $68,0 \mathrm{a}$ & $50 \mathrm{a}$ & $2,55 \mathrm{a}$ & --- \\
\hline $\mathrm{F}_{2}$ & $\begin{array}{l}1^{\mathrm{a}} \text { Apl. difenoconazole } \\
2^{\mathrm{a}} \text { Apl. }\end{array}$ & 100 & 964 a & $34,0 \mathrm{c}$ & $54,0 \mathrm{~b}$ & $63,0 \mathrm{ab}$ & $45 \mathrm{ab}$ & $2,54 \mathrm{a}$ & --- \\
\hline $\mathrm{F}_{3}$ & $\begin{array}{l}1^{\mathrm{a}} \text { Apl. propiconazole } \\
2^{\mathrm{a}} \mathrm{Apl} \text {. }\end{array}$ & 125 & 916 a & $38,0 \mathrm{~b}$ & $57,0 \mathrm{ab}$ & $64,0 \mathrm{a}$ & $44 \mathrm{ab}$ & $2,50 \mathrm{a}$ & --- \\
\hline $\mathrm{F}_{1}$ & sem fungicida & --- & $680 \mathrm{~b}$ & $28,0 \mathrm{~d}$ & $51,0 \mathrm{c}$ & $58,0 \mathrm{~b}$ & $41 \mathrm{~b}$ & $2,31 \mathrm{~b}$ & --- \\
\hline B. Se & sundo ano & & & & & & & & \\
\hline $\mathrm{F}_{3}$ & $\begin{array}{l}1^{\mathrm{a}} \text { Apl. trifloxystrobin } \\
2^{\mathrm{a}} \mathrm{Apl} \text {. difenoconazole }\end{array}$ & $125+100$ & $1582 \mathrm{a}$ & 53,7 a & $68,1 \mathrm{ab}$ & 83,6 a & --- & --- & $21,3 \mathrm{bc}$ \\
\hline $\mathrm{F}_{2}$ & 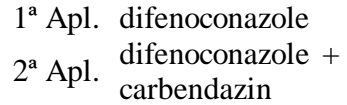 & $\begin{array}{c}100 \\
100+250\end{array}$ & $1495 \mathrm{a}$ & $52,7 \mathrm{a}$ & $67,9 \mathrm{ab}$ & 83,9 a & --- & --- & $20,8 \mathrm{c}$ \\
\hline $\mathrm{F}_{5}$ & $\begin{array}{l}1^{\mathrm{a}} \text { Apl. } \\
2^{\mathrm{a}} \text { Apl. } \\
\begin{array}{l}\text { difenoconoconazole } \\
\text { tricyclazole }\end{array}\end{array}$ & $\begin{array}{c}100 \\
100+187\end{array}$ & $1494 \mathrm{a}$ & 53,8 a & $67,9 \mathrm{ab}$ & $82,0 \mathrm{ab}$ & --- & --- & $20,5 \mathrm{c}$ \\
\hline $\mathrm{F}_{4}$ & $\begin{array}{l}1^{\mathrm{a}} \mathrm{Apl} \text { trifloxystrobin } \\
2^{\mathrm{a}} \mathrm{Apl} \text {. propiconazole }\end{array}$ & $125+150$ & $1476 \mathrm{a}$ & $54,1 \mathrm{a}$ & $68,3 \mathrm{a}$ & $81,9 \mathrm{ab}$ & --- & --- & $24,5 \mathrm{~b}$ \\
\hline $\mathrm{F}_{1}$ & sem fungicida & --- & $1339 \mathrm{~b}$ & $50,6 \mathrm{~b}$ & $67,3 \mathrm{~b}$ & $78,4 \mathrm{~b}$ & --- & --- & $28,7 \mathrm{a}$ \\
\hline
\end{tabular}


No segundo ano, a produtividade da cultura principal foi de $5880 \mathrm{~kg} \mathrm{ha}^{-1}$, correspondendo a 98 sacas ha $^{-1}$ de $60 \mathrm{~kg}$.

Os equipamentos de colheita afetaram o rendimento de grãos inteiros e o índice de colheita (IC) da soca (Tabela 5). A colheita realizada com picador de palha $\left(E_{1}\right)$ propiciou, significativamente, maior rendimento de grãos inteiros e IC que o tratamento sem picador e sem espalhador de palha $\left(E_{3}\right) \mathrm{e}$ estes, por sua vez, não diferiram da colheita com espalhador de palha $\left(\mathrm{E}_{2}\right)$.

Tabela 5. Efeitos de equipamento de colheita sobre o rendimento de grãos inteiros e o índice de colheita (IC) da soca de arroz irrigado $^{1}$

\begin{tabular}{lcc}
\hline Equipamento de Colheita & $\begin{array}{c}\text { Rendimento de } \\
\text { Grãos Inteiros }(\%)\end{array}$ & IC \\
\hline Picador de palha & $54,8 \mathrm{a}$ & $0,42 \mathrm{a}$ \\
Espalhador de palha & $52,3 \mathrm{ab}$ & $0,40 \mathrm{ab}$ \\
Sem picador e espalhador & $51,9 \mathrm{~b}$ & $0,38 \mathrm{~b}$ \\
\hline${ }^{1}$ Médias seguidas pela mesma letra não diferem a 5\% de probabilidade, pelo teste de Tukey
\end{tabular}

Os manejos da palhada influenciaram diversas características da soca (Tabela 6). A altura de plantas foi significativamente menor nos tratamentos onde a palhada foi manejada $\left(\mathrm{TP}_{1}\right.$ e $\left.\mathrm{TP}_{2}\right)$ mostrando que, neles, o crescimento das plantas foi afetado. $\mathrm{O}$ uso da roçadora $\left(\mathrm{TP}_{2}\right)$ reduziu a porcentagem de perfilhos férteis em comparação com os demais, indicando que houve emissão de perfilhos que não resultaram em panículas. No tratamento sem manejo $\left(\mathrm{TP}_{3}\right)$ o número de panículas por área foi maior que no rolo compactador $\left(\mathrm{TP}_{1}\right) \mathrm{e}$ este, por sua vez, superior à roçadora. $\mathrm{O}$ maior número de panículas obtido no $\mathrm{TP}_{3}$ resultou em panículas com menor número de grãos e porcentagem de fertilidade de espiguetas. As plantas que receberam os tratamento $\mathrm{TP}_{1}$ e $\mathrm{TP}_{2}$ tiveram menor desenvolvimento que as do $\mathrm{TP}_{3}$, tanto na altura de plantas como na produção de matéria seca de palha. A roçadora apresentou menor índice de colheita, ou seja, menor relação entre a parte economicamente útil da produção biológica e a biomassa total. Isto se deve à menor fertilidade de perfilhos e ao número de panículas por área. As plantas submetidas aos manejos $\mathrm{TP}_{1}$ e $\mathrm{TP}_{2}$, apresentaram maior porcentagem de grãos manchados. Menores rendimentos de grãos inteiros e industrial total foram obtidos no tratamento em que a roçadora foi empregada. Schiocchet (2001) menciona que a obtenção de alto índice de grãos quebrados na soca deve estar associada à desuniformidade de formação do perfilho e, conseqüentemente, floração e maturação em período mais amplo que o normal.

Assim como no primeiro ano, não houve diferença significativa entre as produtividades de grãos da soca dos tratamentos fungicidas no segundo ano e apenas a da testemunha foi inferior a estas (Tabela 3). Os fungicidas propiciaram maior porcentagem de fertilidade de espiguetas; entretanto, os tratamentos $\mathrm{F}_{4}$ - duas aplicações de trifloxystrobin, $125 \mathrm{~g}$ i.a. ha $^{-1}$, + propiconazole, $150 \mathrm{~g}$ i.a. ha ${ }^{-1} \mathrm{e}$ $\mathrm{F}_{5}$ - primeira aplicação de difenoconazole, $100 \mathrm{~g}$ i.a. ha- ${ }^{-1} \mathrm{e}$ segunda aplicação de difenoconazole, $100 \mathrm{~g}$ i.a. ha-1 + tricyclazole, $187 \mathrm{~g}$ i.a. ha ${ }^{-1}$, não diferiram da testemunha $\left(\mathrm{F}_{1}\right)$. Como se esperava, a porcentagem de grãos manchados foi maior no sem fungicida. Os rendimentos de grãos inteiros dos tratamentos que receberam fungicidas não diferiram de forma significativa e foram significativamente maiores que o da testemunha, o que pode ser conseqüência da maior ocorrência de doenças nos grãos neste tratamento $\left(\mathrm{F}_{1}\right)$. O rendimento industrial de grãos do tratamento $\mathrm{F}_{4}$ - duas aplicações de trifloxystrobin, $125 \mathrm{~g}$ i.a. ha ${ }^{-1}+$ propiconazole, $150 \mathrm{~g}$ i.a. ha ${ }^{-1}$, foi maior que o da testemunha e estes não diferiram dos demais. Não se verificou influência dos tratamentos sobre outras análises de qualidade tecnológica dos grãos, como "centro branco", classificação visual, temperatura de gelatinização e teor de amilose.

Ocorreu interação entre os equipamentos de colheita e os manejos da palhada sobre a produção de matéria seca total e a produtividade (Tabela 7). Independente dos equipamentos de colheita, o tratamento com roçadora $\left(\mathrm{TP}_{2}\right)$ resultou em menor produção de matéria seca e produtividade que os demais

Tabela 6. Efeitos do manejo da palhada sobre diversas características da soca de arroz irrigado ${ }^{1}$

\begin{tabular}{|c|c|c|c|c|c|c|c|c|c|c|}
\hline \multirow{3}{*}{ Manejo da Palhada } & \multirow{3}{*}{$\begin{array}{l}\text { Altura de } \\
\text { Plantas } \\
\text { (cm) }\end{array}$} & \multirow{3}{*}{$\begin{array}{l}\text { Perfilhos } \\
\text { Férteis } \\
\\
(\%)\end{array}$} & \multirow{3}{*}{$\begin{array}{l}\text { Panículas } \\
\left(\mathrm{n}^{\mathrm{o}} \mathrm{m}^{-2}\right)\end{array}$} & \multirow{3}{*}{$\begin{array}{l}\text { Grãos } \\
\left(\mathrm{n}^{\circ} \mathrm{pan}^{-1}\right)\end{array}$} & \multirow{3}{*}{$\begin{array}{c}\text { Fertilidade } \\
\text { Espiguetas } \\
(\%)\end{array}$} & \multirow{3}{*}{$\begin{array}{c}\text { Mat. Seca } \\
\text { de Palha } \\
\qquad\left(\mathrm{g} \mathrm{m}^{2}\right)\end{array}$} & \multirow{3}{*}{ IC } & \multicolumn{3}{|c|}{ Rendimento } \\
\hline & & & & & & & & $\begin{array}{c}\text { Grão } \\
\text { Manchado }\end{array}$ & $\begin{array}{c}\text { Grãos } \\
\text { Inteiros }\end{array}$ & $\begin{array}{l}\text { Industrial } \\
\text { de Grãos }\end{array}$ \\
\hline & & & & & & & & \multicolumn{3}{|c|}{$(\%)$} \\
\hline Rolo compactador $\left(\mathrm{TP}_{1}\right)$ & $71 \mathrm{~b}$ & $85,1 \mathrm{a}$ & $249 \mathrm{~b}$ & $52 \mathrm{a}$ & $81,8 \mathrm{ab}$ & $259,8 \mathrm{~b}$ & $0,43 \mathrm{a}$ & $24,2 \mathrm{a}$ & $54,7 \mathrm{a}$ & $68,6 \mathrm{a}$ \\
\hline Roçadora $\left(\mathrm{TP}_{2}\right)$ & $71 \mathrm{~b}$ & $77,6 \mathrm{~b}$ & $183 \mathrm{c}$ & $50 \mathrm{a}$ & $83,2 \mathrm{a}$ & $233,9 \mathrm{~b}$ & $0,35 \mathrm{~b}$ & $24,8 \mathrm{a}$ & $50,7 \mathrm{~b}$ & $66,8 \mathrm{~b}$ \\
\hline Sem manejo $\left(\mathrm{TP}_{3}\right)$ & $73 \mathrm{a}$ & 86,6 a & $322 \mathrm{a}$ & $44 \mathrm{~b}$ & $80,8 \mathrm{~b}$ & 303,7 a & $0,42 \mathrm{a}$ & $20,4 \mathrm{~b}$ & $53,5 \mathrm{a}$ & $68,2 \mathrm{a}$ \\
\hline
\end{tabular}

Tabela 7. Efeitos da interação equipamento de colheita e manejo da palhada sobre a produção de matéria seca total e a produtividade da soca de arroz irrigado ${ }^{1}$

\begin{tabular}{|c|c|c|c|c|c|c|}
\hline \multirow{3}{*}{ Equipamento de Colheita } & \multicolumn{6}{|c|}{ Manejo da Palhada } \\
\hline & $\begin{array}{c}\text { Rolo } \\
\text { Compactador }\left(\mathrm{TP}_{1}\right)\end{array}$ & $\begin{array}{l}\text { Roçadora } \\
\left(\mathrm{TP}_{2}\right)\end{array}$ & $\begin{array}{l}\text { Sem Manejo } \\
\left(\mathrm{TP}_{3}\right)\end{array}$ & $\begin{array}{c}\text { Rolo } \\
\text { Compactador }\end{array}$ & Roçadora & Sem Manejo \\
\hline & \multicolumn{3}{|c|}{ Matéria Seca Total $\left(\mathrm{g} \mathrm{m}^{-2}\right)$} & \multicolumn{3}{|c|}{ Produtividade $\left(\mathrm{kg} \mathrm{ha}^{-1}\right)$} \\
\hline Picador de palha $\left(E_{1}\right)$ & 548 aA & $336 \mathrm{aB}$ & $609 \mathrm{aA}$ & $1915 \mathrm{aA}$ & $984 \mathrm{aB}$ & $2109 \mathrm{aA}$ \\
\hline Espalhador de palha $\left(\mathrm{E}_{2}\right)$ & $407 \mathrm{bB}$ & $365 \mathrm{aB}$ & $502 \mathrm{bA}$ & $1717 \mathrm{abA}$ & $907 \mathrm{aB}$ & $1717 \mathrm{bA}$ \\
\hline Sem picador e sem espalhador $\left(E_{3}\right)$ & $409 \mathrm{bAB}$ & $378 \mathrm{aB}$ & $477 \mathrm{bA}$ & 1576 bA & $900 \mathrm{aB}$ & $1468 \mathrm{cA}$ \\
\hline
\end{tabular}

${ }^{1}$ Médias seguidas pela mesma letra minúscula, na vertical, ou pela mesma letra maiúscula, na horizontal, não diferem a $5 \%$ de probabilidade, pelo teste de Tukey 
tratamentos. Esses resultados diferem daqueles apresentados por Schiocchet (2001) que, avaliando os efeitos dos manejos da palhada: resteva roçada a $10 \mathrm{~cm}$ do solo, resteva acamada com pranchão de alisamento de solo e resteva mantida intacta, verificou que a produtividade de grãos da soca foi semelhante em cada época de semeadura da cultura principal. $\mathrm{O}$ rolo $\left(\mathrm{TP}_{1}\right)$ e o sem manejo $\left(\mathrm{TP}_{3}\right)$ tiveram maior produção de matéria seca no tratamento picador de palha $\left(\mathrm{E}_{1}\right)$. Quando o rolo foi empregado, as produtividades não diferiram nos tratamentos picador de palha $\left(E_{1}\right)$ e espalhador de palha $\left(E_{2}\right)$, e foram superiores à obtida no sem picador e sem espalhador de palha $\left(\mathrm{E}_{3}\right)$. No tratamento sem manejo da palhada $\left(\mathrm{TP}_{3}\right)$ a maior produtividade foi apresentada pelo picador de palha $\left(\mathrm{E}_{1}\right)$ cerca de 35 sacas de $60 \mathrm{~kg}$ por hectare que, por sua vez, foi superior ao espalhador de palha $\left(E_{2}\right)$ e este ao sem picador e sem espalhador de palha $\left(\mathrm{E}_{3}\right)$. Independente dos equipamentos de colheita, as produtividades dos tratamentos rolo e sem manejo da palhada não diferiram significativamente, indicando que o rolo compactador não teve, neste experimento, o efeito que se esperava, ou seja, o de retardar o crescimento das plantas que não foram pisoteadas pela esteira da colhedora, possibilitando uniformizar a brotação e a maturação das plantas de toda a área cultivada. A área pisoteada pela esteira da colhedora corresponde a $38 \%$ da área total. Possivelmente, o rolo compactador não apresentou benefício à soca devido a colheita da cultura principal ter sido realizada mantendo o solo com lâmina de água e o reinício da irrigação ter sido efetuado imediatamente após a colheita. Efetuando-se a drenagem com antecedência à colheita e se reiniciando a irrigação da soca após a brotação, aproximadamente dez dias após o corte das plantas (Santos et al., 2001), é possível que os danos causados pelas esteiras aos colmos remanescentes sejam menores o que, sem dúvida, possibilitaria a colheita de toda a área. Analisando os resultados da Tabela 7, verifica-se que a combinação dos tratamentos picador de palha e sem manejo é a melhor e a única a ser adotada, considerando-se que o tratamento sem manejo representa economia de tempo e de mão-de-obra, em comparação com o tratamento rolo.

\section{CONCLUSÕES}

1. O picador de palha melhora a qualidade e aumenta a produtividade de grãos da soca, em comparação com o sistema de colheita em que não se o utiliza.
2. A roçadora danifica os colmos das plantas, reduzindo o perfilhamento e a produtividade.

3. Os fungicidas propiciam maiores produtividades e menor incidência de doenças nos grãos e, conseqüentemente, melhor qualidade do produto colhido.

4. Rolo compactador não traz benefícios ao crescimento nem à produtividade da soca de arroz irrigado, ao passo que o espalhador de palha apenas em menor altura de corte.

\section{LITERATURA CITADA}

Chauhan, J.S.; Vergara, B.S.; Lopes, F.S.S. Rice ratooning. Manila: IRRI, 1985. p.1-19. IRRI Research Paper Series, 102

Prabhu, A.S.; Filippi, M.C.; Ribeiro, A.S. Doenças e seu controle. In: Vieira, N.R. de A.; Santos, A.B. dos; Sant'Ana, E.P. (eds.). A cultura do arroz no Brasil. Santo Antônio de Goiás: Embrapa Arroz e Feijão, 1999. p.269-307.

Santos, A.B. dos. Aproveitamento da soca. In: Vieira, N.R. de A.; Santos, A.B. dos; Sant'Ana, E.P. (eds.). A cultura do arroz no Brasil. Santo Antônio de Goiás: Embrapa Arroz e Feijão, 1999. p.463-492.

Santos, A.B. dos; Ferreira, E.; Stone, L.F.; Silva, S.C. da; Ramos, C.G. Manejo de água no comportamento da cultura e da soca de arroz irrigado. Pesquisa Agropecuária Brasileira, Brasília, v.37, n.10, p.1413-1420, 2001.

Santos, A.B. dos; Zimmermann, F.J.P.; Santos, C.; Ramos, C.G. Influência de época de colheita e de altura de corte no aproveitamento da soca de arroz irrigado. In: Congresso Brasileiro de Arroz Irrigado, 1; Reunião da Cultura de Arroz Irrigado, 23, 1999, Pelotas. Anais... A sustentabilidade da cadeia produtiva do arroz irrigado no terceiro milênio. Pelotas: Embrapa Clima Temperado, 1999, p.280-281.

Schiocchet, M.A. Efeito da época de semeadura na produção de grãos da soca do arroz. In: Congresso Brasileiro de Arroz Irrigado, 2; Reunião da Cultura de Arroz Irrigado, 24, 2001, Porto Alegre. Anais... Porto Alegre: IRGA, 2001. p.172-174.

Vergara, B.S.; Lopes, F.S.S.; Chauhan, J.S. Morphology and physiology of ratoon rice. In: International Rice Research Institute (ed.). Rice ratooning. Manila, 1988. p.31-40.

Vieira, N.R. de A.; Santos, A.B. dos; Sant'Ana, E.P. A cultura do arroz no Brasil. Santo Antônio de Goiás: Embrapa Arroz e Feijão, 1999. 633p. 